\title{
Six years of total ozone column measurements from SCIAMACHY nadir observations
}

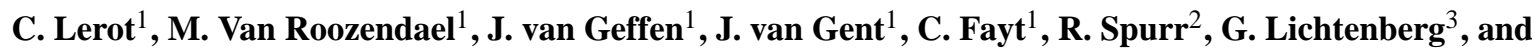 \\ A. von Bargen ${ }^{3}$ \\ ${ }^{1}$ Belgian Institute for Space Aeronomy (BIRA-IASB), Brussels, Belgium \\ ${ }^{2}$ RT Solutions, Inc., Cambridge, Massachusetts, USA \\ ${ }^{3}$ German Aerospace Center (DLR), P.O. Box 1116, 82234 Wessling, Germany
}

Received: 14 October 2008 - Published in Atmos. Meas. Tech. Discuss.: 27 November 2008

Revised: 31 March 2009 - Accepted: 31 March 2009 - Published: 7 April 2009

\begin{abstract}
Total $\mathrm{O}_{3}$ columns have been retrieved from six years of SCIAMACHY nadir UV radiance measurements using SDOAS, an adaptation of the GDOAS algorithm previously developed at BIRA-IASB for the GOME instrument. GDOAS and SDOAS have been implemented by the German Aerospace Center (DLR) in the version 4 of the GOME Data Processor (GDP) and in version 3 of the SCIAMACHY Ground Processor (SGP), respectively. The processors are being run at the DLR processing centre on behalf of the European Space Agency (ESA). We first focus on the description of the SDOAS algorithm with particular attention to the impact of uncertainties on the reference $\mathrm{O}_{3}$ absorption crosssections. Second, the resulting SCIAMACHY total ozone data set is globally evaluated through large-scale comparisons with results from GOME and OMI as well as with ground-based correlative measurements. The various total ozone data sets are found to agree within $2 \%$ on average. However, a negative trend of $0.2-0.4 \% / y e a r$ has been identified in the SCIAMACHY O $\mathrm{O}_{3}$ columns; this probably originates from instrumental degradation effects that have not yet been fully characterized.
\end{abstract}

\section{Introduction}

The state of the ozone layer must be monitored on a longterm basis in order to verify its recovery, which is expected to occur in the next decades as a consequence of the Montreal Protocol and its Amendments phasing out ozone depleting substances (Bodeker et al., 2007). Furthermore, the analysis of the $\mathrm{O}_{3}$ temporal and spatial variabilities is of ma-

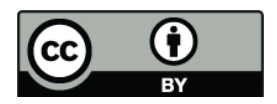

Correspondence to: C. Lerot (christophe.lerot@aeronomie.be) jor importance to improve our understanding of the interactions between ozone, radiation and climate in a changing atmosphere.

UV-visible nadir-viewing spectrometers operating on satellite platforms are key components of the Earth's atmosphere observing system. The ESA's Global Ozone Monitoring Experiment (GOME) (Burrows et al., 1999a) was launched in April 1995 on the ERS-2 satellite. Although still in operation, GOME has lost the ability to provide global coverage as of June 2003 due to a failure of the tape storage system on ERS-2. Launched in March 2002 aboard the European platform ENVISAT, the SCanning Imaging Absorption spectroMeter for Atmospheric CartograpHY (SCIAMACHY) (Bovensmann et al., 1999) has been operational for more than six years and provides global coverage in approximately six days. This instrument alternates between nadir- and limb-viewing modes, respectively for column and stratospheric profile observations. Since August 2004, the GOME and SCIAMACHY instruments have been joined by the Ozone Monitoring Instrument (OMI) (Levelt et al., 2006), a nadir sounder of higher spatial resolution launched on the NASA platform EOS-AURA. Finally, GOME-2 (Munro et al., 2006) was launched in October 2006 on board the METOP satellite, as the first of a series of three identical instruments.

Through their combination, these instruments offer the potential for an assessment of the global total ozone evolution over more than a decade (Loyola et al., 2009). However, this effort requires a careful assessment of the consistency between the different total $\mathrm{O}_{3}$ column data sets. One way to minimize possible discrepancies between instruments is to standardize the retrieval algorithms. The GDOAS algorithm was developed specifically for GOME at the Belgian Institute for Space Aeronomy (BIRA-IASB) during 2003 under

Published by Copernicus Publications on behalf of the European Geosciences Union. 
ESA/ESRIN funding. This algorithm was selected for implementation in version 4 of the GOME data processor (GDP), and more recently for operational processing of GOME-2 on METOP. Here we report on the adaptation of GDOAS to the SCIAMACHY instrument - hereafter named SDOAS to easily distinguish it from the GOME version - and its implementation into the SCIAMACHY Ground Processor (SGP) version 3.0 as part of the standardization of all total ozone retrievals from ESA UV nadir sounders.

In Sect. 2, we give a short description of the main characteristics of the SDOAS algorithm. Section 3 presents a comparative analysis of the available $\mathrm{O}_{3}$ cross-section data sets, while Sect. 4 concentrates on the evaluation of the resulting SCIAMACHY O $\mathrm{O}_{3}$ columns, based on comparisons with correlative satellite and ground-based data sets. Conclusions are drawn in Sect. 5.

\section{Algorithm description}

The main characteristics of the SCIAMACHY Differential Optical Absorption Spectroscopy (SDOAS) algorithm are summarized in this section. More details can also be found in Van Roozendael et al. (2006). SDOAS is based on a two-step approach to derive total ozone columns from SCIAMACHY nadir earthshine radiance measurements. The effective ozone slant column density (SCD) is first derived using the Differential Optical Absorption Spectroscopy (DOAS) technique (Platt, 1994; Platt and Stutz, 2008). This is followed by a conversion to vertical column density (VCD) using calculated air mass factors (AMFs).

\subsection{DOAS fitting}

The model used in the DOAS fitting is based on the BeerLambert extinction law for trace gas absorbers and can be written as

$$
\begin{aligned}
Y(\lambda) \equiv & \ln \left[\frac{I_{\lambda}(\Theta)}{I_{\lambda}^{0}(\Theta)}\right]=-\sum_{g} E_{g}(\Theta) \sigma_{g}(\lambda) \\
& -\sum_{j=0}^{3} \alpha_{j}\left(\lambda-\lambda^{*}\right)^{j}-\alpha_{R} \sigma_{R}(\lambda),
\end{aligned}
$$

where $I_{\lambda}$ and $I_{\lambda}^{0}$ are the earthshine radiance and the solar irradiance at wavelength $\lambda$ respectively, $E_{g}(\Theta)$ is the effective slant column density of gas $g$ along geometrical path $\Theta$, and $\sigma_{g}(\lambda)$ is the trace gas absorption differential cross-section. The second term, a closure polynomial centered at the reference wavelength $\lambda^{*}$, is used to filter out broadband effects such as molecular scattering, aerosol scattering and absorption and reflection from the Earth's surface. The last term represents the Ring reference spectrum $\sigma_{R}(\lambda)$ scaled by the parameter $\alpha_{R}$. The DOAS retrieval consists in a minimization of the weighted least squares difference between measured and simulated optical densities $Y(\lambda)$ for points within the fitting window (325-335 $\mathrm{nm}$ for $\mathrm{O}_{3}$ ).
SCIAMACHY has diffusers mounted on the backside of both elevation (ESM) and azimuth scan modules (ASM). The solar irradiance is measured daily in two consecutive orbits at sunrise, using the ESM diffuser in the first orbit and the ASM diffuser in the second orbit. As a baseline, SDOAS uses the most recent update of the calibrated sun spectrum measured using the ESM diffuser. The wavelength calibration of this spectrum is further improved using a cross-correlation procedure involving a high-resolution reference solar line atlas provided by Chance and Spurr (1997). The resulting calibrated irradiance wavelength grid is the reference grid on which all cross-sections used in the DOAS fitting are interpolated. In the DOAS procedure, allowance is made for a wavelength shift to be applied to the wavelength grid of the earthshine spectrum, so that the spectrum itself can be resampled on the reference irradiance wavelength grid.

The adjusted Ring spectrum (Chance and Spurr, 1997) considers only the Fraunhofer filling-in contribution. A further correction for the molecular Ring effect is applied after the DOAS fit. This is done through application of a scaling factor depending on the $\mathrm{O}_{3}$ AMF (see Sect. 2.2.1 for details). In the DOAS fitting, eight auxiliary parameters are simultaneously fitted in addition to the $\mathrm{O}_{3} \mathrm{SCD}$. These are: an effective temperature for the $\mathrm{O}_{3}$ absorption (derived from the adjustment of $\mathrm{O}_{3}$ cross-sections at two different temperatures), a $\mathrm{NO}_{2} \mathrm{SCD}$, a scaling factor for the Fraunhofer Ring effect correction, four polynomial closure parameters, and a wavelength shift parameter for the earthshine spectrum resampling.

\subsection{SCD to VCD conversion}

The $\mathrm{O}_{3}$ vertical column density $V$ can be derived from the $\mathrm{O}_{3} \mathrm{SCD} E_{O_{3}}$ via the relation:

$V=\frac{\frac{E_{O_{3}}}{M_{R}}+\Phi G A_{\text {cloud }}}{(1-\Phi) A_{\text {clear }}+\Phi A_{\text {cloud }}}$,

where $M_{R}$ is a molecular Ring correction scale factor, $A_{\text {clear }}$ and $A_{\text {cloud }}$ are the AMFs calculated for the atmosphere down to the ground and to the cloud top level respectively. The so-called "Ghost column" $G$ is the quantity of ozone below the cloud top height, and $\Phi$ is the intensity-weighted cloud fraction. The computation of $A_{\text {cloud }}, G$ and $\Phi$ requires additional cloud property information, namely, the cloud fraction, the cloud top height and the cloud top albedo of the observed scenes. These are provided by dedicated cloud algorithms (cf. Sect. 2.2.3).

In practice, the above equation for the VCD is applied iteratively. A column-classified ozone profile climatology is used to provide a unique link between the value of $V$ and the profile to be used in the radiative transfer AMF simulations. We start from an initial guess $V_{0}$ taken from a zonal monthly averaged total ozone climatology provided with the $\mathrm{O}_{3}$ profile climatology TOMS v8 (Bhartia, 2002). AMFs, intensities, the ghost column and molecular Ring scaling are 
computed based on the choice $V_{0}$, and Eq. (2) is then used to generate a new VCD estimate $V_{1}$. This process is repeated until the relative difference between VCD iterations is less than a small number. This iteration procedure was first used in GDP 3.0; for more details see Spurr et al. (2005).

\subsubsection{Molecular Ring correction}

As already mentioned, the Ring spectrum adjustment in the DOAS fitting corrects only for the filling-in of Fraunhofer absorption solar lines due to inelastic rotational Raman scattering (RRS) by air molecules. In addition to this effect, RRS also causes filling-in of atmospheric absorption features. This "telluric" or molecular Ring effect is particularly important for ozone in the UV, and it must be considered for precise total $\mathrm{O}_{3}$ retrievals. It was shown by Van Roozendael et al. (2002) and Coldewey-Egbers et al. (2005) that neglect of the molecular Ring effect results in a systematic underestimation of ozone columns by up to $10 \%$. As the bulk of the $\mathrm{O}_{3}$ column is located in the stratosphere and upper troposphere, a simple yet accurate molecular Ring correction, presented in detail by Van Roozendael et al. (2006), can be obtained by dividing the $\mathrm{O}_{3}$ SCD by a scale factor $M_{R}$ calculated according to the following relation:

$M_{R}=1+\alpha_{R} \overline{\sigma_{R}}\left(1-\frac{\sec \left(\theta_{0}\right)}{(1-\Phi) A_{\text {clear }}+\Phi A_{\text {cloud }}}\right)$,

where $\alpha_{R}$ is the fractional intensity of Raman light obtained from the DOAS fitting procedure, $\overline{\sigma_{R}}$ is the average Ring cross-section calculated over the spectral fitting interval, $\theta_{0}$ is the solar zenith angle, $\Phi$ is the intensity-weighted cloud fraction and $A_{\text {clear }}$ and $A_{\text {cloud }}$ are the AMFs for the clear and cloudy parts of the pixel, calculated as explained in the next sub-section.

\subsubsection{AMF computation}

The AMF calculation is based on the relation

$A=\frac{\ln \left(I_{\text {nog }} / I_{g}\right)}{\tau_{\text {vert }}}$,

where $\tau_{\text {vert }}$ is the vertical optical thickness of ozone and $I_{g}$ and $I_{\text {nog }}$ are the simulated backscatter radiances with and without ozone in the atmosphere, respectively. Simulated radiances are obtained "on-the-fly" using version $2.5+$ of the multiple scattering discrete ordinate radiative transfer model LIDORT. This version uses the pseudo-spherical approximation and applies an additional correction to account for the sphericity of the atmosphere along the line of sight (Spurr, 2004). The radiances are simulated at $325.5 \mathrm{~nm}$; the choice of this wavelength was discussed in Van Roozendael et al. (2002).

In order to account for the scan angle change across a measured pixel, the total radiance is constructed as a weighted sum of radiances simulated for different viewing geometries across the scan. For GOME, a two-point Gauss-Legendre integration has been used for this sum. For SCIAMACHY, a parabolic weighting is applied to results based on the three geometries specified in the level 1 product (start, mid-point and end of the pixel; contributions are weighted according to the ratios 1:4:1). SCIAMACHY pixels are much smaller than those for GOME, and this simple geometry weighting procedure was found to be precise enough for the present work.

\subsubsection{Data bases}

To simulate the radiances reaching the top of the atmosphere, LIDORT requires optical properties to be prescribed for each layer of the atmosphere. These optical properties are obtained from the following input data bases:

- $\mathrm{O}_{3}$ vertical distributions: we use the $\mathrm{O}_{3}$ columnclassified TOMS version 8 climatology (Bhartia, 2002), which provides $\mathrm{O}_{3}$ partial columns in 11 discrete pressure layers.

- The temperature profiles supplied with the TOMS v8 climatology.

- The temperature-dependent $\mathrm{O}_{3}$ cross-sections measured by Bogumil et al. (2003) (see next section).

- The ETOP05 topographic database (available at http:// www.ngdc.noaa.gov/mgg/global/seltopo.html).

- For the surface albedo, the TOMS Lambertian equivalent reflectivity (LER) data at $380 \mathrm{~nm}$ (Herman and Celarier, 1997) are adjusted to values at $335 \mathrm{~nm}$ using the wavelength dependency of the GOME LER data (Koelemeijer et al., 2003) at 335 and $380 \mathrm{~nm}$, as proposed by Boersma et al. (2004).

- The SDOAS algorithm ingests cloud parameters (cloud fraction, cloud top pressure and cloud-top albedo). The latter two are required for a LIDORT calculation to cloud-top.

The cloud properties deserve special consideration. In the prototype algorithm, the three cloud parameters were compiled off-line by running the FRESCO+ cloud algorithm (Koelemeijer et al., 2001; Wang et al., 2008). In FRESCO+, the cloud-top albedo is assumed to be 0.8 , and the other two parameters are fitted using reflectances in and around the $\mathrm{O}_{2} \mathrm{~A}$ band. For high surface albedo scenes (albedo $>0.2$ ), FRESCO+ switches to a snow/ice mode in which the cloud fraction is set to 1 and an effective cloud top albedo and the cloud top pressure are retrieved instead. In the operational algorithm, the geometrical cloud fraction is retrieved using the OCRA algorithm (Loyola, 2000, 2004), while the cloud top height (pressure) and cloud top albedo are derived using the SACURA algorithm (Kokhanovsky et al., 2005, 2008). 


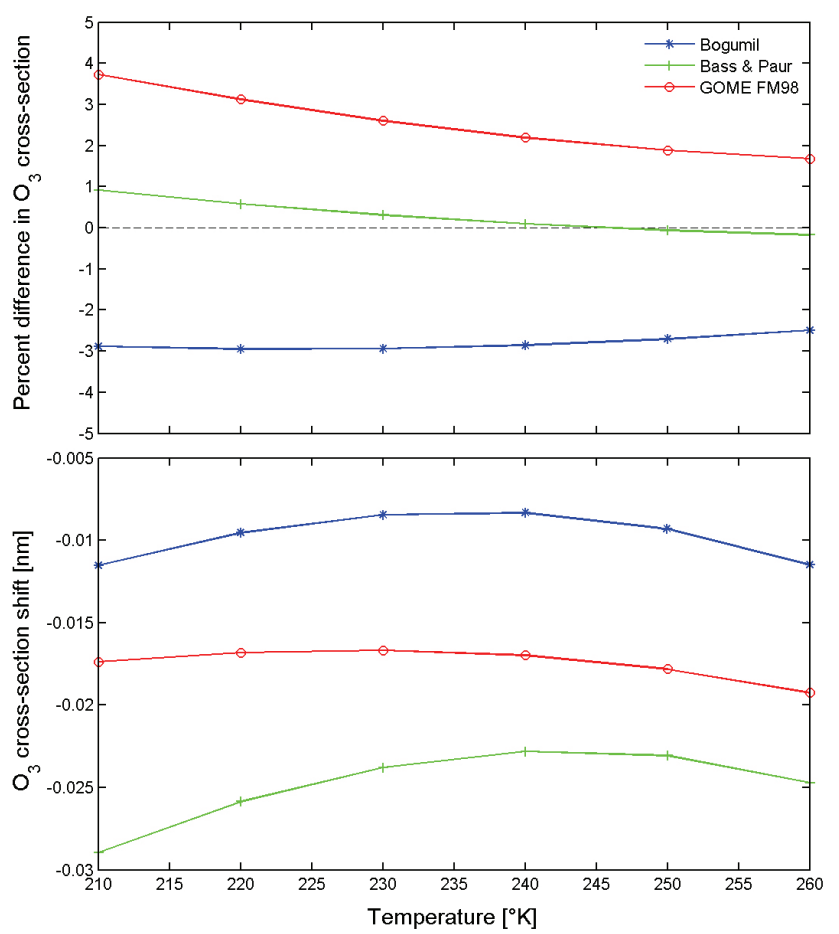

Fig. 1. Mean scale factors (upper panel) and shifts (lower panel) to be applied to the different $\mathrm{O}_{3}$ cross-section sets to match the DM data for temperatures ranging between 210 and $260 \mathrm{~K}$.

\section{$3 \mathrm{O}_{3}$ absorption cross-sections}

The accuracy of total ozone retrievals relies heavily on the quality of the $\mathrm{O}_{3}$ absorption cross-sections. We have intercompared four different data sets available from the literature: the GOME flight model data (GFM) (Burrows et al., 1999b), the SCIAMACHY flight model data (SFM) (Bogumil et al., 2003), the high-resolution Bass and Paur data (BP) (Bass and Paur, 1985; Paur and Bass, 1985) and the highresolution Daumont and Malicet data (DM) (Daumont et al., 1992; Brion et al., 1993; Malicet et al., 1995). These reference cross-sections are given at different temperatures and spectral resolutions. For example, the resolutions at $330 \mathrm{~nm}$ are $0.17 \mathrm{~nm}$ for the GFM, $0.22 \mathrm{~nm}$ for the SFM, $0.05 \mathrm{~nm}$ for the BP data and $0.01 \mathrm{~nm}$ for the DM cross-sections. With the exception of the SFM data (which was measured by SCIAMACHY itself), the other cross-section data sets must be degraded to the SCIAMACHY spectral resolution using effective instrumental lineshapes derived according to Van Roozendael et al. (2002).

\subsection{Intercomparisons of the data sets}

To allow comparison of the various $\mathrm{O}_{3}$ cross-section data sets, a quadratic parameterization of their respective temperature dependencies has been performed.
Following Liu et al. (2007), the DM cross-sections at $273 \mathrm{~K}$ were not used in this analysis, as they are affected by a systematic bias.

Figure 1 shows the mean scale factors and relative shifts applied to the different cross-sections for 6 temperatures ranging from $210 \mathrm{~K}$ to $260 \mathrm{~K}$; this has been done in order to match the DM data in the spectral window $320-340 \mathrm{~nm}$. These two parameters have been simultaneously retrieved using a least-squares fitting procedure. The shifts derived for the SFM and GFM data are close to $-0.01 \mathrm{~nm}$ and $-0.017 \mathrm{~nm}$ respectively, while those derived for the BP data range between $-0.029 \mathrm{~nm}$ and $-0.023 \mathrm{~nm}$, depending on the temperature. The amplitudes of the BP and DM differential cross-sections agree within $1 \%$, while the amplitude of the GFM data is from $1.7 \%$ to $3.7 \%$ larger and that of the SFM cross-sections is about $3.0 \%$ smaller. For effective temperatures commonly observed in the atmosphere, the scale factor between the SFM and GFM data is about $5 \%$.

\subsection{Wavelength registration}

To optimize the relative alignment between $\mathrm{O}_{3}$ cross-sections and measured absorption spectra, a pre-shift value generally must be applied to compensate small inaccuracies in the wavelength calibration of the reference data. In this work, the pre-shift values are determined by adjustment within the DOAS procedure as part of a series of test retrievals. The retrieved pre-shift value is closely linked to the wavelength registration of the irradiance spectrum and is therefore dependent on the wavelength calibration scheme.

Figure 2 shows the mean pre-shifts (averaged over all pixels with solar zenith angle (SZA) less than $60^{\circ}$ ) retrieved from the DOAS procedure using the SFM data for 60 orbits in 2003 equally distributed over the seasons. As can be seen, they are strongly dependent on the applied wavelength calibration procedure. Since the impact of a pre-shift error on the ozone column is important (about $2.5 \%$ per $0.01 \mathrm{~nm}$ shift error), it is necessary to use a pre-shift properly adapted to the wavelength calibration scheme. The black symbols in Fig. 2 represent the pre-shifts derived using the original wavelength grid provided with level-1 data product. These values varying strongly from an orbit to another, it is clear that the default level-1 wavelength calibration is not stable enough, and that a fine-tuning of the wavelength registration is therefore required. In practice, this is performed by shifting the wavelength grid of the irradiance spectrum in the fitting interval $(325.0-335.0 \mathrm{~nm})$ until Fraunhofer lines are closely aligned with a reference atlas of solar lines (Chance and Spurr, 1997). This procedure, which is used as baseline for the total $\mathrm{O}_{3}$ retrievals, leads to an optimal mean pre-shift of $+0.020 \mathrm{~nm}$ for the SFM cross-sections (Fig. 2 red symbols). A more complex wavelength calibration procedure based on the shift of the wavelength grid in 4 consecutive micro-windows between 320 and $360 \mathrm{~nm}$ leads to a pre-shift of $\sim+0.008 \mathrm{~nm}$ (Fig. $2-$ green symbols). The 


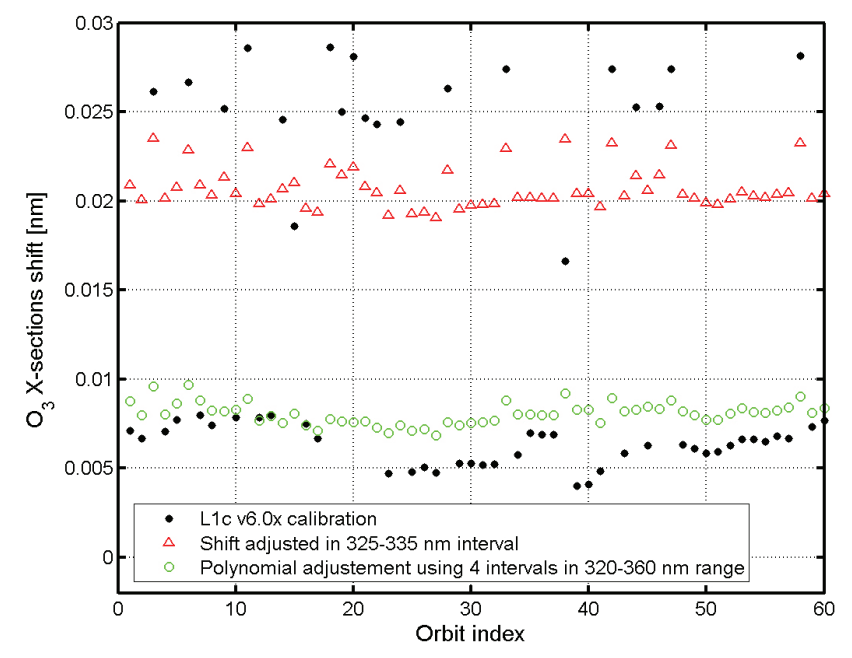

Fig. 2. $\mathrm{SFM} \mathrm{O}_{3}$ cross-section pre-shift values determined from fits to a representative data set of 60 SCIAMACHY orbits, considering the impact of applying different wavelength calibration schemes (see text for a comprehensive description of the symbols). The preshift values are directly linked to the calibration procedure and an inappropriate pre-shift may lead to important errors on the total $\mathrm{O}_{3}$ columns.

optimal mean pre-shifts derived using the simple wavelength calibration procedure for the other cross-section data sets are $+0.011 \mathrm{~nm},+0.028 \mathrm{~nm}$ and $+0.035 \mathrm{~nm}$ for DM, GFM and $\mathrm{BP}$, respectively. These values are consistent with the relative shift values displayed on Fig. 1 and also with the direct comparison of the GFM and SFM data sets realized by Weber et al. (2007). For total ozone column retrievals from GOME spectra, the GOME data processor (GDP) version 4 uses the GFM cross-sections with a pre-shift of $+0.016 \mathrm{~nm}$ (Van Roozendael et al., 2006). The difference with the preshift value determined in this work for SCIAMACHY probably originates from uncertainties on the absolute wavelength calibration of both instruments, possibly also related to the known asymmetry of the GOME slit function in the 325$335 \mathrm{~nm}$ region (Van Roozendael et al., 2002).

\subsection{SDOAS fitting performance}

Residuals from the DOAS fits have been examined for each reference $\mathrm{O}_{3}$ cross-section data set in order to test their quality. The respective root mean square (RMS) residual errors averaged over all pixels with $\mathrm{SZA} \leq 50^{\circ}$ from the aforementioned 60 -orbit set are $2.523 \times 10^{-3}, 2.208 \times 10^{-3}$, $2.225 \times 10^{-3}$ and $2.137 \times 10^{-3}$ for the BP, DM, GFM and SFM data sets, respectively. A significantly larger RMS value is obtained with BP cross-sections in comparison to the values from the other data sets, which is in agreement with Liu et al. (2007) where it is shown that the BP data are much noisier. The lowest RMS are obtained using the SFM cross-sections.

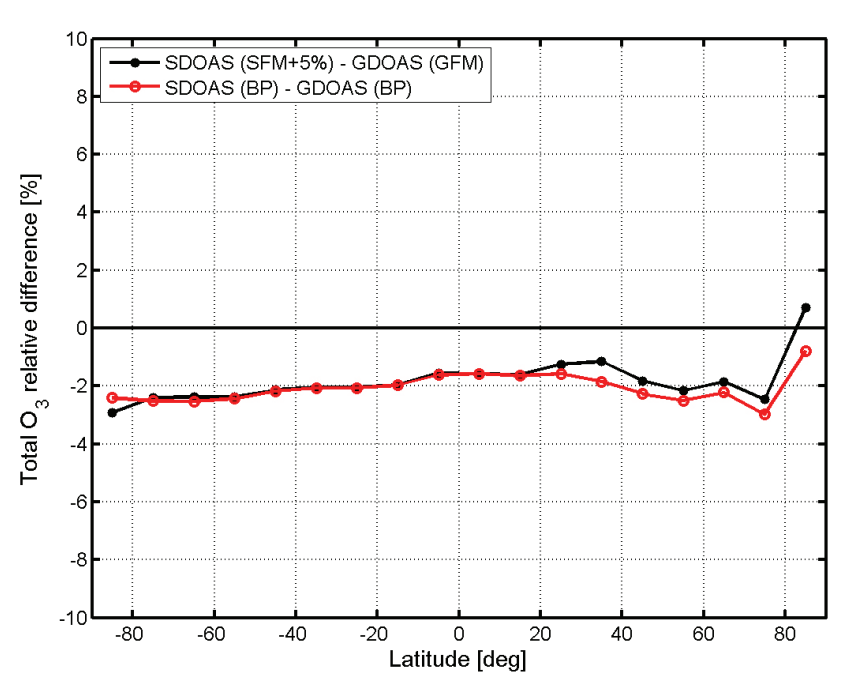

Fig. 3. Comparison of the total $\mathrm{O}_{3}$ columns derived from SCIAMACHY and GOME using the G/SDOAS algorithm for 20 colocated orbits between January and April 2003. The comparisons are shown for the $\mathrm{O}_{3}$ columns derived using the flight model crosssections or the Bass and Paur data.

Based on these results, the $\mathrm{SFM} \mathrm{O}_{3}$ cross-sections at $223 \mathrm{~K}$ and $243 \mathrm{~K}$ have been selected as reference data for ozone retrievals from SCIAMACHY. Using cross-sections at two temperatures enables us to retrieve an effective temperature in the DOAS procedure and to take the temperature dependence of the ozone absorption into account (Richter and Burrows (2002), Spurr et al. (2005)). Given the amplitude difference between the GFM (used as a baseline in GDP v4) and SFM data (see Sect. 3.1), a positive scale factor of $+5 \%$ should be applied to SFM data in order to ensure consistency between the total $\mathrm{O}_{3}$ columns derived from SCIAMACHY and GOME measurements.

Figure 3 compares total $\mathrm{O}_{3}$ columns retrieved from SCIAMACHY using the SFM cross-sections (scaled by $+5 \%$ ) to coincident GOME $\mathrm{O}_{3}$ columns derived using the GFM data for a sample of 20 orbits distributed between January and April 2003. A residual bias of $-2 \%$ is clearly visible. However, this bias does not originate from the cross-sections. Indeed, a similar bias is found when the BP data, previously convolved to respective instrument resolutions, is used in the retrievals. Despite efforts made to identify the origin of this bias and its possible link with calibration issues (level 0-1 processing), no satisfying explanation could be found so far. Nevertheless, to improve consistency between GOME and SCIAMACHY total $\mathrm{O}_{3}$ columns, it was decided to reduce the scale factor applied to the SFM data from 5\% to $3 \%$. The SCIAMACHY bias and its time-depencence are further addressed in Sect. 4. 

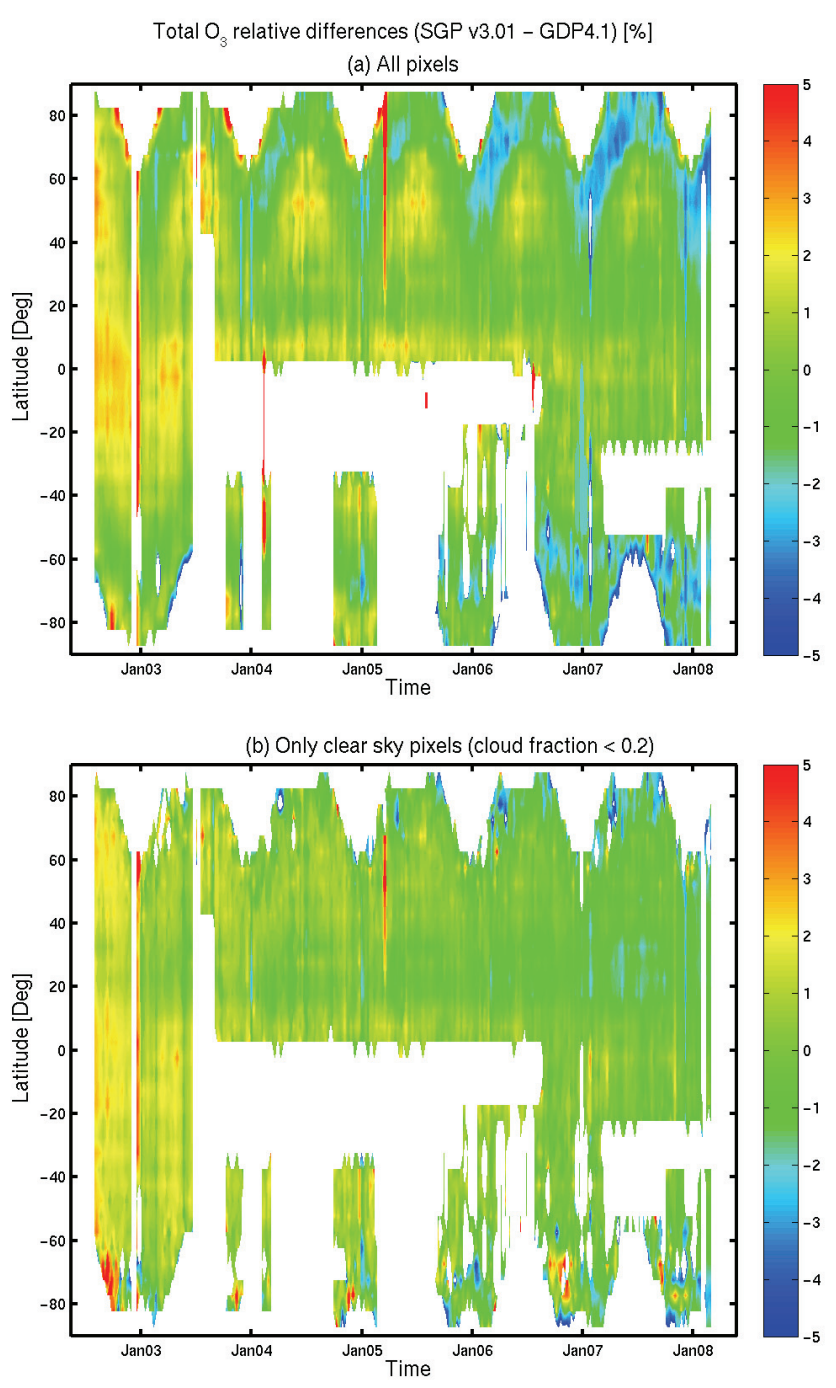

Fig. 4. Relative differences between the total $\mathrm{O}_{3}$ columns retrieved from the SCIAMACHY Ground Processor v3.01 and from the GOME instrument with GDP 4.1 versus latitude and time. The differences after June 03 should be carefully considered due to the loss of the global coverage of the GOME instrument. Top panel: differences for all pixels; lower panel: differences for cloud free pixels (cloud fraction $<0.2$ ).

\section{Evaluation of SCIAMACHY total ozone data set}

Version 3 of the SCIAMACHY offline processor (SGP) represents a major upgrade (von Bargen et al., 2007). With a requirement to have an uninterrupted and fully consistent record of ozone data combining the GOME and SCIAMACHY measurements, one of the main goals of this SGP upgrade has been the incorporation of the SDOAS algorithm. In this version, measured radiances (Level $1 \mathrm{~b}$ data v6) are first calibrated using the same algorithms as those implemented in the SciaL1C tool (Lichtenberg et al., 2006; Sli- jkhuis, 2005; Frerick and von Bargen, 2007). As noted in Sect. 2, the operational algorithm uses the OCRA/SACURA algorithm combination to derive cloud information.

In the present work, the SCIAMACHY SGP v.3.01 total $\mathrm{O}_{3}$ data product released in early 2008 has been evaluated using correlative satellite and ground-based data.

\subsection{Comparison with GOME $\mathrm{O}_{3}$ measurements}

Due to the ERS-2 tape storage failure in June 2003, a global comparison of GOME and SCIAMACHY is only possible from July 2002 to June 2003. Later comparisons are based on limited regions in the Northern Hemisphere and, to a lesser extent, the Southern Hemisphere. Here, we use the GOME GDP 4.1 data product.

To obtain coincident data sets, daily maps at the resolution of $1.0^{\circ} \times 1.0^{\circ}$ in latitude-longitude are produced by applying a spatial regridding to each product. Thus, $\mathrm{O}_{3}$ columns can easily be compared on a daily basis. In order to study possible dependencies, other parameters such as latitude, SZA, $\mathrm{O}_{3}$ column can also be binned on the same latitude-longitude grid. The temporal dependencies are deduced by examining the evolution of the daily $\mathrm{O}_{3}$ differences.

Figure 4 (upper panel) shows the latitudinal and temporal dependencies for the relative differences between the total $\mathrm{O}_{3}$ columns derived from SGP 3.01 and GDP 4.1. Despite the good overall agreement (differences generally less than $1 \%$ ), systematic positive and negative differences are present for latitudes larger than $50^{\circ}$ in summer and winter, respectively. We found that these differences are related to the choice of cloud algorithm used in the operational environment (OCRA/ROCINN (Loyola, 2004) for GDP4.1 and OCRA/SACURA for SGP 3.1). Indeed, taking clear sky pixels alone (cloud fraction lower than 0.2), these difference patterns are not observed (Fig. 4, lower panel). Moreover, most of the large $\mathrm{O}_{3}$ differences correlate with cloud parameter differences, as shown in Fig. 5. Positive differences are generally found when the SGP cloud top height is higher than the GDP cloud top height, which leads to a larger ghost column correction. On the other hand, negative differences are related to higher values of cloud-top albedo used in SGP (this parameter has a strong impact on the air mass factor). We have also observed that large cloud-top albedo differences correlate with notable $\mathrm{O}_{3}$ differences only for pixels with similar values of cloud fraction. Conversely, many pixels with large (positive) cloud-top albedo differences also possess large (negative) cloud fraction differences; this compensatory effect limits the impact on the ozone column.

Further inspection of Fig. 4 reveals that $\mathrm{O}_{3}$ column differences are slightly larger at the beginning of the time series. This is confirmed in Fig. 6, where the temporal evolution of the SGP-GDP relative differences for all latitudes between $+10^{\circ}$ and $+60^{\circ}$ is presented. A trend in the differences $(-0.40 \% / y e a r)$ is clearly visible. 

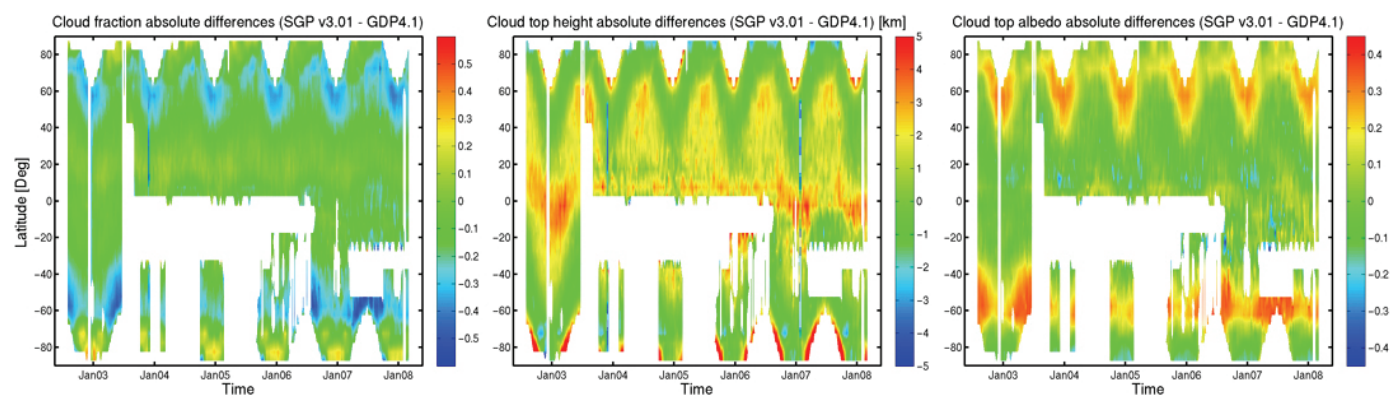

Fig. 5. Absolute differences between the cloud parameters (cloud fraction, cloud top height and cloud top albedo) from OCRA/ROCINN in GDP 4.1 and from OCRA/SACURA in SGP 3.01.

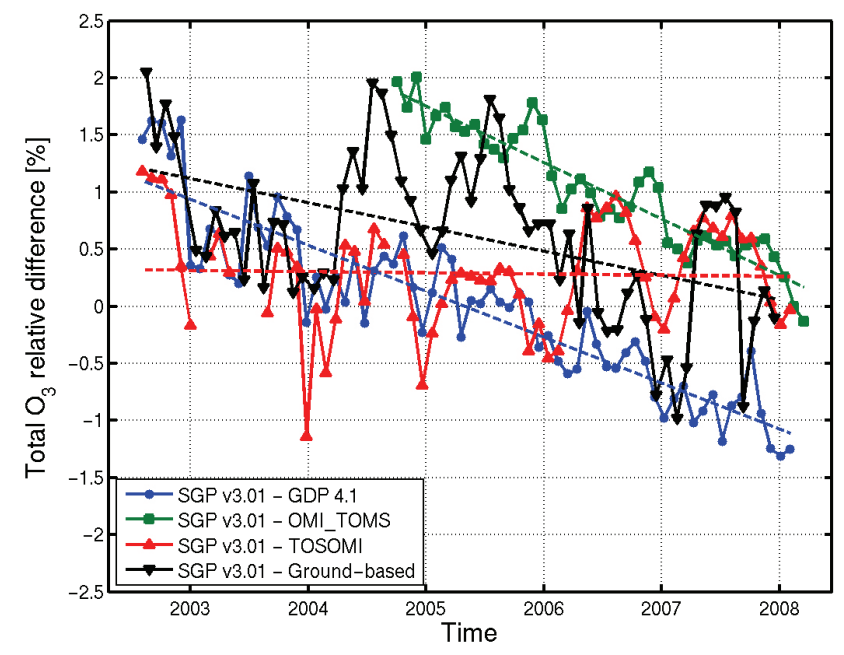

Fig. 6. Temporal trend of the monthly averaged relative differences between the total $\mathrm{O}_{3}$ columns derived from SGP 3.01 and from other instruments and/or algorithms for all measurements realized in the latitude interval $\left[-60^{\circ},+60^{\circ}\right]\left(\left[+10^{\circ},+60^{\circ}\right]\right.$ for GOME).

\subsection{Comparison with $\mathrm{OMI} \mathrm{O}_{3}$ columns}

The SGP total $\mathrm{O}_{3}$ columns have been compared to OMTO3 ozone columns (collection 3) derived from the OMI instrument with the TOMS V8.5 retrieval algorithm (Bhartia, 2002). Such global comparisons are interesting since the OMTO3 product is based on a totally different algorithm. The OMTO3 data are given on a daily grid with a $1.0^{\circ} \times 1.0^{\circ}$ resolution (latitude $\times$ longitude); they can be downloaded from the website ftp://toms.gsfc.nasa.gov/pub/ omi/data/ozone/.

Figure 7 presents time series of zonally averaged total $\mathrm{O}_{3}$ relative differences. The global agreement is satisfactory with differences generally less than $2 \%$. However, discrepancies are much larger in ozone hole conditions as well as for extreme solar zenith angles. Moreover, the overall agree-

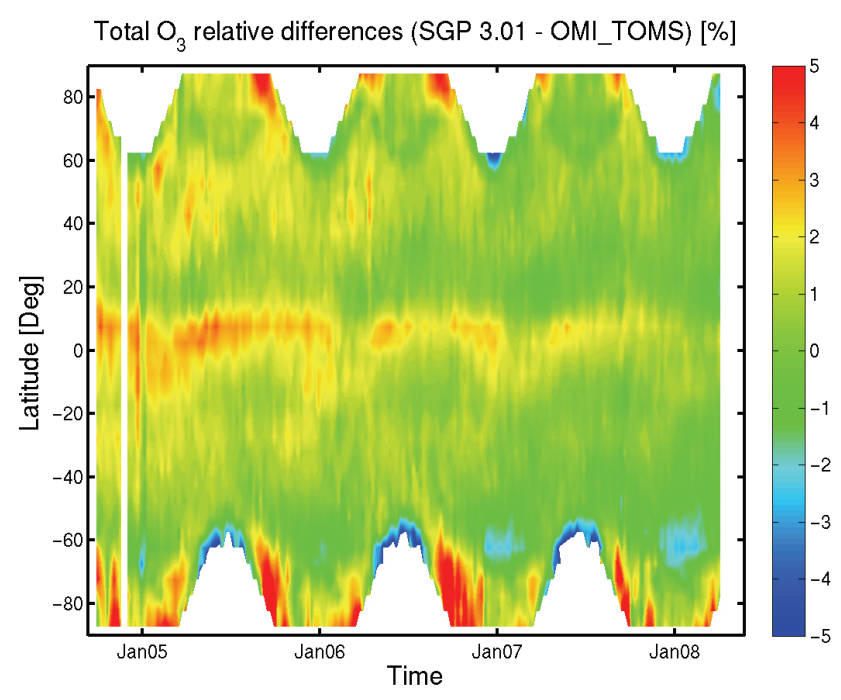

Fig. 7. Relative differences between the total $\mathrm{O}_{3}$ columns derived from SGP 3.01 and from the OMI instrument with the TOMS V8.5 algorithm versus latitude and time (from August 2004 until March 2008).

ment between the two instruments significantly improves with time. This is clearly visible in Fig. 6 where the differences averaged for all latitudes between $-60^{\circ}$ and $+60^{\circ}$ reach $+2 \%$ at the end of 2004 , after which they decrease smoothly and become very small in 2008 . The trend measured in these comparisons equals to $-0.49 \% / y e a r$. Total ozone columns are also derived from the OMI spectra using another algorithm based on the DOAS technique (Veefkind et al., 2006). Recent comparisons (Kroon et al., 2008) have shown that the differences between the OMTO3 and the OMI-DOAS (v1.0.5; collection 3) columns, close to $0 \%$ in October 2004, gradually become more negative and reach about $-1 \%$ in April 2008. Considering the OMI-DOAS instead of the OMTO3 columns for the SGP-OMI comparisons would consequently lead to a trend of larger amplitude. 


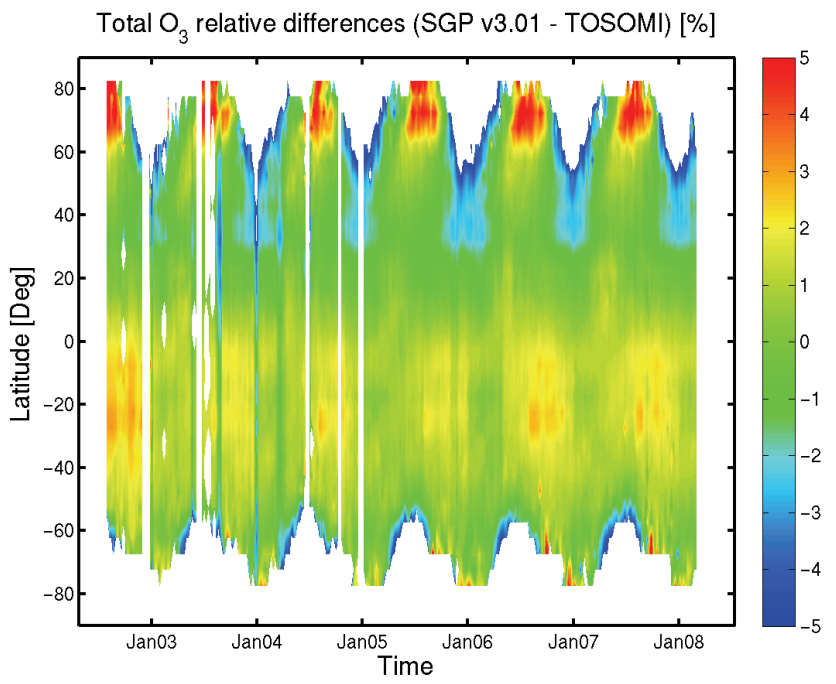

Fig. 8. Relative differences between the total $\mathrm{O}_{3}$ columns derived from SCIAMACHY using SGP 3.01 or TOSOMI versus latitude and time.

\subsection{Comparison with TOSOMI $\mathrm{O}_{3}$ columns}

Here, we compare the SGP $\mathrm{O}_{3}$ columns to those derived using TOSOMI (version 0.42), a scientific SCIAMACHY total $\mathrm{O}_{3}$ retrieval algorithm designed at KNMI (Eskes et al., 2005). The TOSOMI total $\mathrm{O}_{3}$ columns are distributed via the Tropospheric Emission Monitoring Internet Service (www.temis.nl). Note that both TOSOMI and SDOAS use the same level-1 data, so the impact of algorithmic differences can be highlighted.

In Fig. 8, the total $\mathrm{O}_{3}$ relative differences between SGP and TOSOMI are plotted against latitude and time. The overall agreement is very good, the differences being generally lower than $1 \%$ except over Northern Mid-latitudes and the Southern Tropics, where slight annual seasonalities in the differences are found. Also, the SGP columns are systematically larger than the TOSOMI columns in Northern Polar regions during summer months.

Figure 6 shows time-series of $\mathrm{O}_{3}$ relative differences for all pixels located in the latitude band $\left[-60^{\circ},+60^{\circ}\right]$. Note that there is almost no long-term trend. This indicates that TO$\mathrm{SOMI} \mathrm{O}_{3}$ columns tend to drift with time in a similar manner to those obtained from the SGP. Therefore, this suggests that the trend observed in other comparisons is related to an instrumental problem or to inaccuracies in the calibration (level 0 to 1 processing), but not to the retrieval algorithm.

\subsection{Comparison with ground-based measurements}

For these comparisons, measurements from 55 groundbased stations have been considered, among which 19 are equipped with Brewer instruments, 29 with Dobson spectrometers and 7 with UV-visible spectrometers. The source of the ground-based data is the World Ozone and Ultraviolet Radiation Data Centre (www.woudc.org) and the Network for the Detection of Atmospheric Composition Change (www.ndsc.ncep.noaa.gov). For each station, the nearest $\mathrm{SGP} \mathrm{O}_{3}$ column (within a maximum distance of $250 \mathrm{~km}$ ) is compared daily to the temporally closest ground-based column.

For a selection of stations sampling different latitudes, Fig. 9 illustrates the relative differences between the SGP $3.01 \mathrm{O}_{3}$ columns and correlative ground-based measurements. For each station, a sine function with a slope parameter has been fitted to the time-series (red curves in Fig. 9). The results display a systematic negative gradient bias, confirming the negative trend in $\mathrm{SGP} \mathrm{O}_{3}$ columns already identified from satellite/satellite comparisons. The amplitude of the trend ranges between $-0.04 \%$ and $-1.11 \%$ per year, depending on the station.

The relative differences between SGP and ground-based total $\mathrm{O}_{3}$ columns monthly averaged on all stations located in the $\left[-60^{\circ},+60^{\circ}\right]$ latitude interval are shown in Fig. 6. Again, the negative trend of the SCIAMACHY $\mathrm{O}_{3}$ columns is apparent and consistent with a similar trend observed from SGPGDP and SGP-OMI comparisons.

\subsection{Summary of comparison results}

From the above comparisons, we conclude that the overall agreement between SGP 3.01 total $\mathrm{O}_{3}$ columns and correlative satellite data derived from GOME and OMI is good. Indeed, in the $\left[-60^{\circ},+60^{\circ}\right]$ latitude interval, the total ozone relative differences are less than $1 \%$ for $50 \%$ of the pixels, less than $2 \%$ for $85 \%$ of them, and differences seldom exceed 5\%. With respect to ground-based data, dispersion of the differences is larger due to less favourable collocation of air mass soundings, but on the whole there is no appreciable systematic bias and $76 \%$ of the measurements agree within $5 \%$ for the complete set of ground stations used in this study.

Despite the overall good agreement, comparisons also reveal that the SCIAMACHY total $\mathrm{O}_{3}$ columns suffer from a small but significant decreasing trend, ranging between -0.21 and $-0.49 \% / y e a r$. This time dependent bias must be connected to the bias already identified in Sect. 3. Since the TOSOMI data (based on the same level-1 files) is characterized by a similar trend, one suspects problems related to instrument degradation and/or to level- 0 to 1 processing. Possible time-dependent inaccuracies in the radiometric calibration procedure (leading to intensity offsets in the spectra) could be responsible for such a trend in the ozone columns. Indeed, the method is sensitive to additive errors and to wavelength-dependent multiplicative errors in this procedure. The next version of the SGP operational algorithm will have improved corrections for the radiometric degradation of SCIAMACHY based on the so-called "m-factors" (Bramstedt, 2008). The hope is that this may improve the temporal stability of the SCIAMACHY $\mathrm{O}_{3}$ columns. 

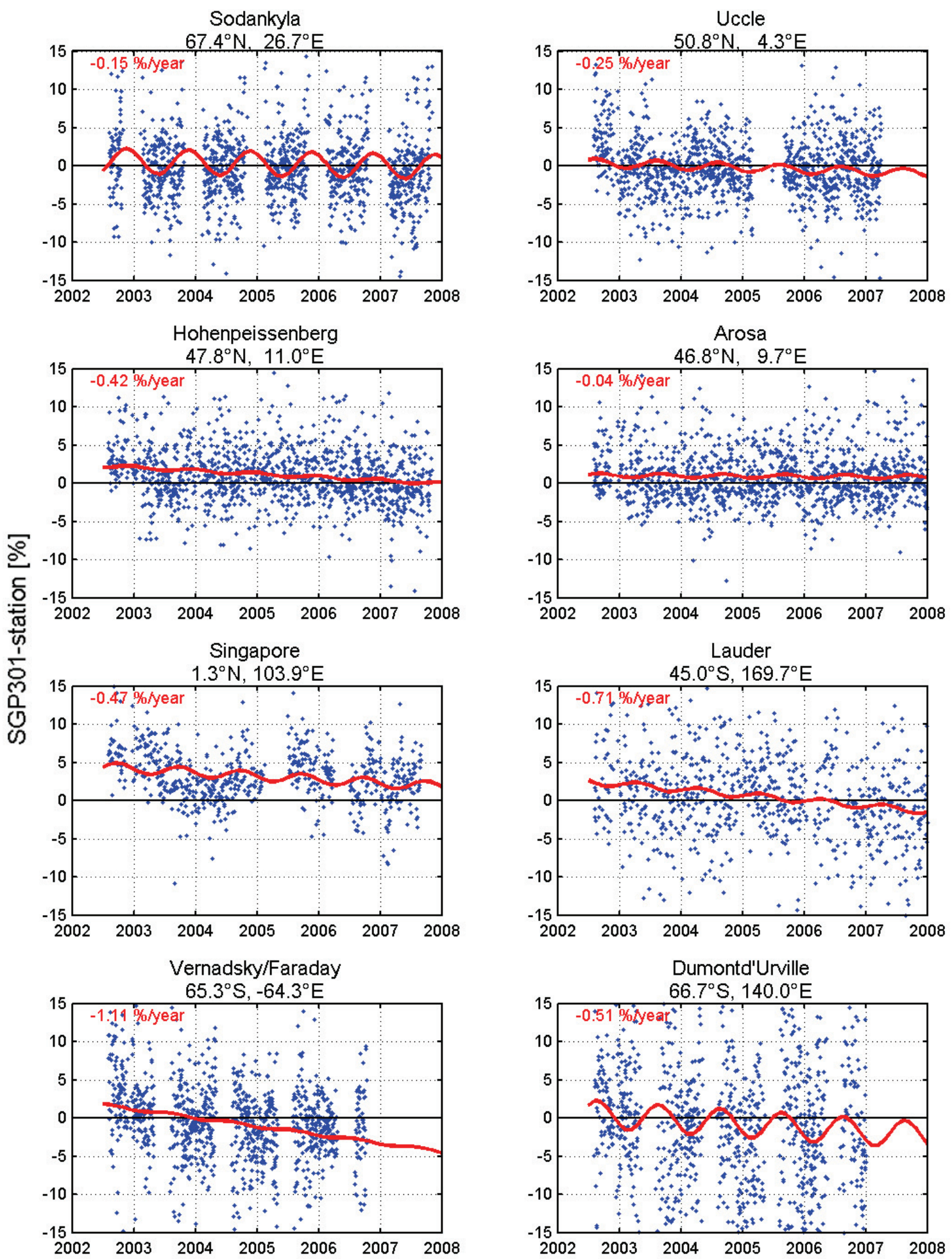

Fig. 9. Time series of the relative differences between the SGP and ground-based total $\mathrm{O}_{3}$ columns for different stations. The sinusoidal functions fitted through the dots highlight possible trend and seasonality in the differences. 


\section{Conclusions}

SDOAS is an algorithm for retrieval of total $\mathrm{O}_{3}$ columns from SCIAMACHY nadir backscattered measurements and has been implemented within the ESA operational environment SGP version 3. For the retrieval settings, special efforts have been made to assess the consistency of current $\mathrm{O}_{3}$ crosssection reference data sets. Best fits to SCIAMACHY spectra have been obtained using the Bogumil et al. (2003) data set pre-shifted by $+0.02 \mathrm{~nm}$. An additional empirical scale factor of $+3 \%$ compensates for (1) amplitude differences between the SCIAMACHY and GOME flight model cross-sections, and (2) an unresolved bias in the SCIAMACHY columns.

The entire SCIAMACHY total $\mathrm{O}_{3}$ column data set from the operational environment SGP v3.01 has been compared to measurements derived from other instruments or algorithms. Comparisons with the GOME $\mathrm{O}_{3}$ columns from GDP 4.1 show excellent agreement, especially for clear sky pixels, for which relative differences are generally less than $1 \%$. However, for pixels contaminated by clouds, differences may reach a few percent, and this is due mainly to the different cloud algorithms implemented in the GOME and SCIAMACHY operational systems. Future work should focus on better understanding these differences and better assessing the appropriateness of the cloud algorithms used for trace gas retrievals. Comparisons with TOSOMI and OMTO3 columns as well as with ground-based measurements also show good agreement, with relative differences generally less than $2 \%$ and $5 \%$ for satellite/satellite and satellite/ground-based comparisons, respectively.

Despite the overall good agreement, validation results also reveal the existence of a small but significant temporal trend in the SCIAMACHY total $\mathrm{O}_{3}$ columns, in the form of a decrease of approximately $0.2-0.4 \%$ /year. Although the cause of this trend is unresolved, we have shown that it does not originate from the retrieval algorithm. We think that the reason is to be found from consideration of instrumental degradation and/or inaccuracies in the Level 0 to 1 (calibration) processing.

The impact of future improvements to the SCIAMACHY ground segment on the ozone column accuracy will be regularly monitored as part of activities of the SCIAMACHY Quality Working Group.

Acknowledgements. The authors would like to thank all the members of the SCIAMACHY Quality Working Group for their fruitful collaboration. The European Space Agency is gratefully acknowledged for use of SGP v3.01 data, available to the users at the D-PAC server (FTP address 195.37.183.37, ftp-ops-dp.eo.esa.int).

Edited by: C. von Savigny

\section{References}

Bass, A. M. and Paur, R. J.: The ultraviolet cross-sections of ozone, I, The measurements, in: Atmospheric Ozone, edited by: Zerefos, C. S., Ghazi, A., and Reidel, D., Norwell, Mass., 606-610, 1985.

Bhartia, P. K.: OMI algorithm theoretical basis document, 2, OMI ozone products, NASA Goddard Space Flight Center, Greenbelt, Maryland, USA, available at http://eospso.gsfc.nasa.gov/eos_homepage/for_scientists/atbd/ viewInstrument.php?instrument=13, 2002.

Bodeker, G. E., and Waugh, D .W. (Lead Authors), Akiyoshi, H., Braesicke, P., Eyring, V., Fahey, D. W., Manzini, E., Newchurch, M. J., Portmann, R. W., Robock, A., Shine, K. P., Steinbrecht, W., and Weatherhead, E. C.: The Ozone Layer in the $21^{\text {st }}$ Century, Chapter 6 in Scientific Assessment of Ozone Depletion: 2006, Global Ozone Research and Monitoring Project-Report No. 50, 572 pp., World Meteorological Organization, Geneva, Switzerland, 2007.

Boersma, K. F., Eskes, H. J., and Brinksma, E. J.: Error analysis for tropospheric $\mathrm{NO}_{2}$ retrieval from space, J. Geophys. Res., 109, D04311, doi:10.1029/2003JD003962, 2004.

Bogumil, K., Orphal, J., Homann, T., Voigt, S., Spietz, P., Fleischmann, O. C., Vogel, A., Hartmann, M., Bovensmann, H., Frerick, J., and Burrows, J. P.: Measurements of molecular absorption spectra with the SCIAMACHY pre-flight model: instrument characterization and reference data for atmospheric remotesensing in the 230-2380 nm region, J. Photochem. Photobiol. A., 157, 167-184, 2003.

Bovensmann, H., Burrows, J., Buchwitz, M., Frerick, J., Noel, S., Rozanov, V., Chance, K., and Goede, A.: SCIAMACHY: Mission objectives and measurement modes, J. Atmos. Sci., 56, 127 150, 1999.

Bramstedt, K.: Calculation of SCIAMACHY M-Factors, TN IFE-SCIA-TN-2007-01-CalcMFactor, Issue 1, Institute of Environmental Physics, Bremen, available at: http://www.iup. uni-bremen.de/sciamachy/mfactors/mfactor-TN-1-0.pdf, 2008.

Brion, J., Chakir, A., Daumont, D., and Malicet, J.: High-resolution laboratory absorption cross sections of $\mathrm{O}_{3}$. Temperature effect, Chem. Phys. Lett., 213(5-6), 610-612, 1993.

Burrows, J.P., Weber, M., Buchwitz, M., Rozanov, V., LadstätterWeissenmayer, A., Richter, A., DeBeek, R., Hoogen, R., Bramstedt, K., Eichmann, K.-U., Eisinger, M., and Perner, D.: The Global Ozone Monitoring Experiment (GOME): mission concept and first scientific results, J. Atmos. Sci., 56, 151-175, 1999a.

Burrows, J., Richter, A., Dehn, A., Deters, B., Himmelmann, S., Voigt, S., and Orphal, J.: Atmospheric remote sensing reference data from GOME: Part 2. Temperature-dependent absorption cross-sections of $\mathrm{O}_{3}$ in the 231-794 nm range, J. Quant. Spectrosc. Ra., 61, 509-517, 1999 b.

Chance, K. and Spurr, R.: Ring effect studies: Rayleigh scattering including molecular parameters for rotational Raman scattering, and the Fraunhofer spectrum, Appl. Optics, 36, 5224-5230, 1997.

Coldewey-Egbers, M., Weber, M., Lamsal, L. N., de Beek, R., Buchwitz, M., and Burrows, J. P.: Total ozone retrieval from GOME UV spectral data using the weighting function DOAS approach, Atmos. Chem. Phys., 5, 1015-1025, 2005 , http://www.atmos-chem-phys.net/5/1015/2005/. 
Daumont, M., Brion, J., Charbonnier, J., and Malicet, J.: Ozone UV spectroscopy, I: Absorption cross-sections at room temperature, J. Atmos. Chem., 15, 145-155, 1992.

Eskes, H. J., van der A, R. J., Brinksma, E. J., Veefkind, J. P., de Haan, J. F., and Valks, P. J. M.: Retrieval and validation of ozone columns derived from measurements of SCIAMACHY on Envisat, Atmos. Chem. Phys. Discuss., 5, 4429-4475, 2005, http://www.atmos-chem-phys-discuss.net/5/4429/2005/.

Frerick, J. and von Bargen, A.: SCIAMACHY Level 1b-1c Processing - The SciaL1c Command-line Tool Software User's Manual, ENV-SUM-DLR-SCIA-0071, Issue 6.0/B, available at: http://earth.esa.int/services/SciaL1C_tool/SciaL1c_SUM_6. 0B.pdf, 2007.

Herman, J. R. and Celarier, E. A.: Earth surface reflectivity climatology at 340-380 nm from TOMS data, J. Geophys. Res., 102(D23), 28003-28012, doi:10.1029/97JD02074, 1997.

Kroon, M., Veefkind, J. P., de Haan, J. F., McPeters, R. D., Bhartia, P. K., Balis, D., Petropavlovskikh, I., Froidevaux, L., Shetter, R., and Levelt, P. F.: Absolute quality of the EOS Aura Ozone Monitoring Instrument total ozone columns and vertical ozone profiles, presented at EOS Aura 2008 Science Team Meeting, available at: http://avdc.gsfc.nasa.gov/index.php?site $=1072744097 \backslash$ \#validation, 2008.

Koelemeijer, R. B. A., Stammes, P., Hovenier, J. W., and de Haan, J. F.: A fast method for retrieval of cloud parameters using oxygen A band measurements from the Global Ozone Monitoring Experiment, J. Geophys. Res., 106(D4), 3475-3490, 2001.

Koelemeijer, R. B. A., de Haan, J. F., Hovenier, J. W., and Stammes, P.: A database of spectral surface reflectivity in the range 335$772 \mathrm{~nm}$ derived from 5.5 years of GOME observations, J. Geophys. Res., 108(D2), 4070, doi:10.1029/2002JD002429, 2003.

Kokhanovsky, A. A., Rozanov, V. V., Burrows, J. P., Eichmann, K.U., Lotz, W., and Vountas, M.: The SCIAMACHY cloud products: algorithms and examples from ENVISAT, Adv. Space Res., 36, 789-799, 2005.

Kokhanovsky, A. A., Rozanov, V. V., Vountas, M., Lotz, W., Bovensmann, H., and Burrows, J. P.: SCIAMACHY 1b to 2 OL Processing, Algorithm Theoretical Basis Document, Semi-Analytical CloUd Retrieval Algorithm for SCIAMACHY/ENVISAT, ENV-ATB-IFE-SCIA-0003, Issue 2.0, available at: http://earth.esa.int/pub/ESA_DOC/ENVISAT/ SCIAMACHY/ENVI95.pdf, 2008.

Levelt, P. F., van den Oord, G. H. J., Dobber, M. R., Malkki, A., Visser, H., de Vries, J., Stammes, P., Lundell, J. O. V., and Saari, H.: The Ozone Monitoring Instrument, IEEE T. Geosc. Remote, 44(5), 1093-1101, 2006.

Lichtenberg, G., Kleipool, Q., Krijger, J. M., van Soest, G., van Hees, R., Tilstra, L. G., Acarreta, J. R., Aben, I., Ahlers, B., Bovensmann, H., Chance, K., Gloudemans, A. M. S., Hoogeveen, R. W. M., Jongma, R. T. N., Noël, S., Piters, A., Schrijver, H., Schrijvers, C., Sioris, C. E., Skupin, J., Slijkhuis, S., Stammes, P., and Wuttke, M.: SCIAMACHY Level 1 data: calibration concept and in-flight calibration, Atmos. Chem. Phys., 6, 5347-5367, 2006,

http://www.atmos-chem-phys.net/6/5347/2006/.

Liu, X., Chance, K., Sioris, C. E., and Kurosu, T. P.: Impact of using different ozone cross sections on ozone profile retrievals from Global Ozone Monitoring Experiment (GOME) ultraviolet measurements, Atmos. Chem. Phys., 7, 3571-3578, 2007, http://www.atmos-chem-phys.net/7/3571/2007/.

Loyola, D.: Cloud retrieval for SCIAMACHY, in: Proceedings of ERS-ENVISAT Symposium, Gothenburg, Sweden, 16-20 October 2000.

Loyola, D.: Automatic cloud analysis from polar-orbiting satellites using neural network and data fusion techniques, in: Proceedings of IEEE International Geoscience and Remote Sensing Symposium, 4, 2530-3534, 2004.

Loyola, D. G., Coldewey-Egbers, M., Dameris, M., Garny, H., Stenke, A., Van Roozendael, M., Lerot, C., Balis, D., and Koukouli, M.: Global long-term monitoring of the ozone layer - a prerequisite for predictions, Int. J. Remote. Sens., in press, 2009.

Malicet, C., Daumont, D., Charbonnier, J., Parisse, C., Chakir, A., and Brion, J.: Ozone UV spectroscopy, II: Absorption crosssections and temperature dependence, J. Atmos. Chem., 21, 263273, 1995.

Munro, R., Eisinger, M., Anderson, C., Callies, J., Corpaccioli, E., Lang, R., Lefebvre, A., Livschitz, Y., and Pérez Albiñana, A.: GOME-2 on Metop: From in-orbit verification to routine operations, in: Proceedings of EUMETSAT Meteorological Satellite Conference, Helsinki, Finland, 12-16 June 2006.

Paur, R. J. and Bass, A. M.: The ultraviolet cross-sections of ozone, II, Results and temperature dependence, in: Atmospheric Ozone, edited by: Zerefos, C.S., Ghazi, A., and Reidel, D., Norwell, Mass., 611-616, 1985.

Platt, U.: Differential optical absorption spectroscopy (DOAS), in: Air Monitoring by Spectroscopic Techniques, edited by: Sigrist, M. W., Chemical Analysis Series, Wiley, New York, 127, 27-84, 1994.

Platt,U. and Stutz, J.: Differential optical absorption spectroscopy, Physics of Earth and Space Environments, Springer-Verlag, Berlin Heidelberg, doi:10.1007/978-3-540-75776-4, 2008.

Richter A. and Burrows, J. P.: Retrieval of Tropospheric $\mathrm{NO}_{2}$ from GOME Measurements, Adv. Space Res., 29(11), 1673-1683, 2002.

Slijkhuis, S.: ENVISAT-1 SCIAMACHY Level 0 to $1 \mathrm{c}$ Processing Algorithm Theoretical Basis Document, ENV-ATB-DLR-SCIA-0041, Issue 4, available at: http://envisat.esa.int/services/sample_products/sciamachy/ documentation/SCIAMACHY/atbd_0_to1c.pdf, 2005.

Spurr, R. J. D.: LIDORT V2PLUS: A comprehensive radiative transfer package for UV/VIS/NIR nadir remote sensing, in: Proceedings of SPIE, 5235, Remote sensing of clouds and the atmosphere, 89-100, doi:10.1117/12.511103, 2004.

Spurr, R., Loyola, D., Thomas, W., Balzer, W., Mikusch, E., Aberle, B., Slijkhuis, S., Ruppert, T., Van Roozendael, M., Lambert, J.C., and Soebijanta, T.: GOME level 1-to-2 data processor version 3.0: a major upgrade of the GOME/ERS-2 total ozone retrieval algorithm, Appl. Optics, 44(33), 7196-7209, 2005.

Van Roozendael, M., Soebijanta, V., Fayt, C., and Lambert, J.-C. (Eds.): Investigation of DOAS issues affecting the accuracy of the GDP version 3.0 total ozone product, in ERS-2 GOME GDP 3.0 implementation and delta verification, Rep. ERSE-DTEXEOAD-TN-02_0006, 97-129, Eur. Space Res. Inst., Eur. Space Agency, Frascati, Italy, available at: http://earth.esrin.esa.it/pub/ ESA_DOC/GOME/gdp3/gdp3.pdf, 2002.

Van Roozendael, M., Loyola, D., Spurr, R., Balis, D., Lambert, J.-C., Livschitz, Y., Valks, P., Ruppert, T., Kenter, P., Fayt, C., and Zehner, C.: Ten years of GOME/ERS-2 to- 
tal ozone data - The new GOME data processor (GDP) version 4: 1. Algorithm description, J. Geophys. Res., 111, D14311, doi:10.1029/2005JD006375, 2006.

Veefkind, J. P., de Haan, J. F., Brinksma, E. J., Kroon, M., and Levelt, P. F.: Total ozone from the ozone monitoring instrument (OMI) using the DOAS technique, IEEE T. Geosci. Remote Sens., 44, 5, 1239-1244, doi:10.1109/TGRS.2006.871204, 2006.

Von Bargen, A., Schröder, T., Doicu, A., Kretschel, K., Lerot, C., VanRoozendael, M., Kokhanovsky, A., Vountas, M., Bovensmann, H., Hess, M., Aberle, B., and Schreier, F.: SCIAMACHY Level 1b-2 Data Processing: Update of Off-line Data Processor to Version 3.0, Third Workshop on the Atmospheric Chemistry Validation of ENVISAT (ACVE-3), ESA-SP-642, Frascati, 2007.
Wang, P., Stammes, P., van der A, R., Pinardi, G., and van Roozendael, M.: FRESCO+: an improved $\mathrm{O}_{2}$ A-band cloud retrieval algorithm for tropospheric trace gas retrievals, Atmos. Chem. Phys., 8, 6565-6576, 2008,

http://www.atmos-chem-phys.net/8/6565/2008/.

Weber, M., Lamsal, L. N., and Burrows, J. P.: Improved SCIAMACHY WFDOAS total ozone retrieval: Steps towards homogenising long-term total ozone datasets from GOME, SCIAMACHY, and GOME2, in: Proceedings of Envisat Symposium 2007, Montreux, Switzerland, 23-27 April 2007, ESA SP-636, available at: http://www.iup.uni-bremen.de/UVSAT_ material/papers/weber_envsymp2007.pdf, July 2007. 